\title{
Seleção de clones de batata com resistência múltipla à pinta preta e aos vírus $\mathrm{X}$ e $\mathrm{Y}$
}

\author{
Selection of potato clones for multiple resistances to early blight, PVY and PVX \\ Diogo Gonçalves Neder ${ }^{\mathrm{I}}$ César Augusto Brasil Pereira Pinto" ${ }^{\mathrm{II}}$ Dheyne Silva Melo ${ }^{\mathrm{III}}$ \\ Andre Luiz Lepre ${ }^{\mathrm{IV}}$ Leandro dos Santos Peixoutov
}

\section{RESUMO}

O objetivo do presente trabalho foi selecionar clones de batata com elevado desempenho agronômico e resistência à pinta preta e aos vírus $X$ e Y. Para tanto, foram realizados 57 cruzamentos entre clones portadores dos alelos $R y_{a d g}$ e Rx1, e a cultivar 'Chiquita', resistente à pinta preta (Alternaria solani). Na safra das águas de 2004, 57 famílias clonais foram avaliadas em campo e 331 clones selecionados considerando a aparência de tubérculos. Desse total de clones, avaliados em mais dois experimentos no verão de 2005, 180 foram selecionados por meio do marcador SCAR RYSC3 como portadores do alelo $R y_{\text {adg }}$. Também foram realizadas uma avaliação de desempenho agronômico na safra de inverno de 2006 e uma avaliação de resistência à pinta preta nas safras de verão de 2007 e 2008. Paralelamente, foi utilizado um marcador CAPS visando à seleção de clones portadores do gene Rx1. Dessa forma, combinando os resultados dos marcadores moleculares com os de campo, agrupados via índices de seleção, foi possível selecionar 20 clones de alto desempenho agronômico, resistentes à pinta preta e portadores

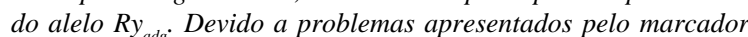
CAPS, apenas sete destes foram analisados e um identificado como portador do alelo $\mathrm{Rx} 1$.

Palavras-chave: avaliação agronômica, marcador molecular, resistência genética, Potato virus $X$, Potato virus $Y$, Alternaria solani.

\section{ABSTRACT}

The purpose of this study was to select potato clones with high agronomic performance and resistant to early blight,
Potato Virus $Y(P V Y)$ and Potato Virus $X(P V X)$. Crossings were done among progenitors carrying the $R y_{\text {adg }}$ and $R x 1$ alleles for resistance to PVY and PVX and the cultivar 'Chiquita', which presents high levels of resistance to early blight (Alternaria solani). In the rainy season of 2004, 57 clonal families were evaluated in the field and 331 clones were selected based on tuber appearance. These clones were field evaluated in two trials in the rainy season of 2005 and 180 clones were selected for Ry allele with the SCAR marker designed RYSC3. Another agronomic evaluation was done in the winter season of 2006 and early blight was evaluated in the rainy seasons of 2007 and 2008. Simultaneously a CAPS marker was used to select for the presence of Rx1 allele. Combining the results from these experiments we were able to select 20 clones presenting high agronomic performance, resistance to early blight and carrying the $R y_{\text {adg }}$ allele. The use of CAPS marker has practical difficulties due to production of poor amplification products to be digested with the DdeI enzyme and should be changed for another marker which shows more efficiency.

Key words: evaluate agronomic, Marker assisted selection, genetic resistance, Potato virus $X$, Potato virus $Y$, Alternaria solani.

\section{INTRODUÇÃO}

São conhecidas mais de 100 doenças bióticas que afetam a cultura da batata, causadas por diferentes espécies de fungos, vírus e viróides, bactérias, nematóides e fitoplasma. Segundo

IDepartamento de Agronomia, Universidade Federal Rural de Pernambuco (DEPA/UFRPE), 52171-900, Recife, PE, Brasil. Email: dgneder@hotmail.com. Autor para correspondência.

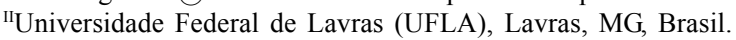

IIICentro de Tecnologia Canavieira (CTC), Piracicaba, SP, Brasil.

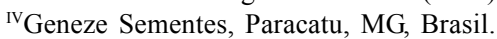

'Instituto Federal de Educação, Ciência e Tecnologia Baiano (IFBAIANO), Guanambi, BA, Brasil. 
GEBAHARDT \& VALKONEN (2001), a ação desses patógenos promove a redução anual da produção mundial de batata em um quarto do seu potencial, gerando uma perda estimada de 100 milhões de toneladas a cada ano. No Brasil, entre as diversas doenças que já foram relatadas, destacam-se como as mais comuns a pinta preta (Alternaria solani (Ellis \& G. Martin) L.R. Jones \& Grout), um dos principais fatores limitantes do cultivo das águas, podendo causar perdas consideráveis pela desfolha precoce das plantas; o vírus Y da batata (Potato virus Y - PVY), agente de uma das principais doenças viróticas da cultura e o vírus $\mathrm{X}$ (Potato virus $\mathrm{X}-\mathrm{PVX}$ ), que apresenta importância, especialmente pelo efeito sinérgico com outros vírus, aumentando drasticamente as perdas.

A natureza da resistência genética a essas doenças é predominantemente quantitativa para a pinta preta (CHRIST \& HAYNEY, 1997), contrastando com a resistência ao PVY e PVX basicamente monogênicas, conferidas por genes de hipersensibilidade, $\mathrm{Ny}$ e $\mathrm{Nx}$, e de resistência extrema, designados Ry e Rx, preferidos por conferir uma resistência mais efetiva, o que restringe o desenvolvimento dos patógenos (COCKERHAM, 1970; ROSS, 1986). Três genes Ry foram localizados por mapeamento molecular dos cromossomos da batata. O gene $\mathrm{Ry}_{\text {sto }}$, derivado de $\mathrm{S}$. stoloniferum, e o $\mathrm{Ry}_{a d g}$, derivado de $\boldsymbol{S}$. tuberosum ssp. andigena, foram mapeados no cromossomo XII (FLIS et al., 2005; SONG et al., 2005) e no XI (HÄMÄLÄINEN et al., 1997), respectivamente, e o gene $\mathrm{Ry}_{c h c}$, derivado de $\boldsymbol{S}$. chacoense, foi mapeado na extremidade do cromossomo IX (SATO et al., 2006). Os genes Rx foram identificados em acessos de S.tuberosum ssp andigena (Schultz \& Raleigh (1933) apud ROSS, 1986; COCKERHAM, 1970) e em S. acaule (ROSS, 1986) e receberam as denominações de $\mathrm{Rx} 1$ e $\mathrm{Rx} 2$, respectivamente, tendo sido mapeados nos cromossomos XII e V ( GEBHARDT \& VALKONEN, 2001).

Trabalhos realizados no Brasil com o objetivo de desenvolver genótipos resistentes à pinta preta foram realizados por MARTINS \& PINTO (1996), que avaliaram genótipos provenientes de um cruzamento dialélico envolvendo oito genitores, sendo identificada a cultivar 'Chiquita' como a de mais alta capacidade geral de combinação. De forma semelhante, SIMON (2005) avaliou diferentes clones de batata, selecionando genótipos que associam alto nível de resistência à pinta preta e tolerância ao calor. Clones resistentes à pinta preta foram selecionados também por BRUNE et al. (1999) e BRUNE et al. (1998).

Clones com resistência extrema aos vírus PVY e PVX foram obtidos por SILVA(2000) e GADUM et al. (2003), a partir de cruzamentos biparentais entre clones portadores dos alelos Rx1 e Ry adg na forma simplex. Posteriormente, RIBEIRO et al. (2006) selecionaram clones duplex (Ry Ry ry ry), empregando o marcador SCAR desenvolvido por KASAI et al. (2000).

O presente trabalho objetivou selecionar clones com resistência à pinta preta e resistência extrema aos vírus $\mathrm{X}$ e $\mathrm{Y}$, associada a um bom desempenho agronômico.

\section{MATERIAL E MÉTODOS}

\section{Material Experimental}

A população base utilizada no presente estudo consistiu de 2280 clones, provenientes de famílias obtidas de cruzamentos biparentais entre a cultivar 'Chiquita' e os 57 clones designados JUG. A cultivar 'Chiquita' apresenta alta capacidade geral de combinação para resistência à pinta preta, produção e peso específico de tubérculos (MARTINS \& PINTO, 1996). Já os clones JUG, obtidos por GADUM et al. (2003), são portadores dos genes $\mathrm{Ry}_{\text {adg }}$ e Rx1 de resistência, respectivamente, aos vírus $\mathrm{Y}$ e X.

\section{Avaliação agronômica}

Quatro experimentos foram conduzidos na área experimental do Departamento de Biologia da Universidade Federal de Lavras (UFLA). O primeiro foi realizado na safra de inverno de 2004, para avaliação de 57 famílias, em delineamento em blocos casualizadas (DBC), com quatro repetições e parcelas de 10 clones de primeira geração, totalizando 40 clones por família. $\mathrm{O}$ espaçamento foi de $0,50 \mathrm{mx} 0,80 \mathrm{~m}$, e as cultivares testemunhas foram: 'Monalisa', 'Asterix' e 'Achat'. Nessa etapa, foi avaliada a produção de tubérculos ( $\mathrm{g}$ planta $\left.^{-1}\right)(\mathrm{PT})$ e o peso específico de tubérculos (PE), mas a seleção dos clones foi baseada exclusivamente na aparência dos tubérculos.

Os 334 clones de segunda geração selecionados foram avaliados na safra das águas de 2005, em dois experimentos, sendo um em látice simples duplicado 14x14, com 221 clones e quatro testemunhas ('Ágata', 'Asterix', 'Atlantic' e 'Monalisa'), e outro em DBC, com três repetições e 113 clones mais as cultivares 'Ágata', 'Asterix' e 'Monalisa', sendo ambos os experimentos realizados com duas plantas por parcela e espaçamento de $0,35 \mathrm{x} 0,80 \mathrm{~m}$. Anotaram-se a PT (g planta $\left.^{-1}\right)$, a porcentagem de tubérculos graúdos (PG), o peso médio de tubérculos (gramas) (PM) e o PE.

Dos 334 clones, foram selecionados 180 portadores do alelo $\mathrm{Ry}_{\text {adg }}$ (ver adiante), os quais foram submetidos a uma nova avaliação de desempenho em 
campo (clones de terceira geração), realizada na safra de inverno de 2006. Foi empregado um DBC com quatro repetições e parcelas de duas plantas espaçadas a $0,35 \times 0,80 \mathrm{~m}$, sendo e utilizadas como testemunhas as cultivares 'Asterix', 'Atlantic', 'Chiquita' e 'Monalisa'. Os caracteres avaliados foram os mesmos dos experimentos anteriores e acrescida a aparência de tubérculos (AT), avaliada por meio de uma escala de notas variando de 1,0 (pior aparência) a 5,0 (melhor aparência).

Os dados dos quatro experimentos foram submetidos a uma análise de variância individual com o programa estatístico SAS (2000) e utilizados nas estimativas do coeficiente de variação ambiental $\left(\mathrm{CV}_{\mathrm{e}}\right)$ e genético $\left(\mathrm{CV}_{\mathrm{g}}\right)$, da razão $\mathrm{CV}_{\mathrm{e}} / \mathrm{CV}_{\mathrm{g}}$ e da herdabilidade no sentido amplo $\left(h^{2} a\right)$.

\section{Avaliação da resistência à pinta preta}

Foram conduzidos dois experimentos simultaneamente nas safras das águas de 2007 e de 2008 (quarta e quinta gerações clonais), sendo empregados apenas os clones portadores do alelo Ryadg. O delineamento empregado em ambos os experimentos foi um alfa-látice 13 x 14, com duas repetições e parcelas de quatro plantas espaçadas de $0,35 \times 0,80 \mathrm{~m}$. Os tratamentos foram 170 clones mais 12 testemunhas, sendo seis cultivares ('Asterix', 'Atlantic', 'Caesar', 'Chiquita', 'Monalisa' e 'Vivaldi') e seis clones de elite do programa de melhoramento da UFLA. Em um dos experimentos, foram incluídas bordaduras internas com a cultivar 'Monalisa', para disseminação do inóculo, o qual foi introduzido em campo via macerado de ramas desidratadas e infectadas, aplicado aos 40 e 50 dias após o plantio (DAP). O outro experimento foi mantido na ausência de pinta preta pela utilização da combinação dos fungicidas clorothalonil + mancozeb. Os caracteres avaliados foram PT, PG, PM, PE, AT e resistência à pinta preta. A resistência foi avaliada no experimento com inoculação e realizada por três avaliadores, sendo utilizada a escala diagramática de REIFSCHNEIDER et al. (1984) aos 80 DAP, 85 DAP e 90 DAP. As notas foram usadas para estimar a área abaixo da curva de progressão da doença (AACPD), empregando-se a metodologia de SHANER \& FINNEY (1977).

Os dados foram submetidos a uma análise de variância pelo SAS (2000), considerando cada experimento individualmente, a análise conjunta com e sem inóculo em um mesmo ano e a análise conjunta dos dois anos. Foram estimados o coeficiente de variação ambiental $\left(\mathrm{CV}_{\mathrm{e}}\right)$ e genético $\left(\mathrm{CV}_{\mathrm{g}}\right)$, a razão $\mathrm{CV}_{\mathrm{e}} /$ $\mathrm{CV}_{\mathrm{g}}$ e a herdabilidade no sentido amplo $\left(\mathrm{h}^{2} \mathrm{a}\right)$.
Foram selecionados os 60 clones mais resistentes à pinta preta dos 170 avaliados empregando o índice de seleção de MULAMBA \& MOCK (1978) e considerando a medida da AACPD e o diferencial de produção obtido (diferença de produção de tubérculos no experimento com e sem inoculação).

Seleção sequencial

Empregou-se o índice de seleção sequencial (LAMBERT et al., 2005) para cada caráter utilizando a média aritmética dos dados proveniente das cinco gerações clonais para os caracteres PT, PM, PG, PE e AT. Em seguida, estes foram combinados empregando o índice de MULAMBA \& MOCK (1978) e selecionados 20 clones de melhor desempenho entre os 60 identificados como resistentes à pinta preta.

Identificação do alelo Ry $y_{\text {adg }}$

A reação de PCR, para identificar genótipos portadores do alelo $\mathrm{Ry}_{\text {adg }}$, foi realizada misturando-se os seguintes reagentes com as respectivas concentrações: $250 \mu \mathrm{M}$ DNTP's (mistura equitativa de ATP, GTP, CTP e TTP), 0,6 unidades de Taq DNA polimerase, $0,26 \mu \mathrm{M}$ de cada iniciador, tampão de reação

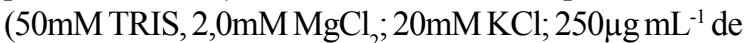
albumina soro bovino; $1 \%$ de ficoll $400 ; 1 \mathrm{mM}$ de tartrazine, 22,5ng de DNA genômico e água pura até completar o volume de $10 \mu 1$. Utilizou-se o par de primers SCAR designado de RYSC3 (KASAI et al., 2000), que amplifica uma região dentro do gene Ry, produzindo fragmentos de $321 \mathrm{pb}$.

As reações de amplificação foram realizadas em microtubos de $0,2 \mathrm{~mL}$, utilizando termociclador PCT100 (MJ Research, Inc.USA), nas seguintes condições: desnaturação inicial de $92^{\circ} \mathrm{C}$ por 4 min, seguida de 35 ciclos a $94^{\circ} \mathrm{C}$, para desnaturação, e $60^{\circ} \mathrm{C}$, para o anelamento, ambos por 45 segundos, e elongação a $72^{\circ} \mathrm{C}$ por $1 \mathrm{~min}$, seguida de uma extensão final a $72^{\circ} \mathrm{C}$, por $5 \mathrm{~min}$.

Os produtos da reação foram separados por eletroforese em gel de agarose a 1,2\%, em tampão TBE (TRIS, ácido bórico e EDTA), em corrente de $100 \mathrm{~V}$, por uma hora. Os fragmentos de DNA foram corados com brometo de etídio a uma concentração de $0,5 \mathrm{ng} \mu \mathrm{l}^{-1}$, por 20 minutos sob agitação. $O$ gel foi fotografado em câmara digital Kodak DC290 Zoom, em luz ultravioleta.

\section{Identificação do alelo Rx1}

A metodologia empregada para seleção de clones portadores do alelo RX1 baseou-se em BENDAHMANE (1997) e consistiu de uma amplificação, com o par deiniciadores CP60, com a seguinte sequência: 5' CAGCCTACCGCGAAAGTGCCTTCG 3' e 
5'GCCAACCCCACGAGTTTCT CACTGAC3' e uma digestão do produto da PCR com a enzima de restrição DdeI.

A reação de PCR foi realizada para $30 \mu \mathrm{lem}$ microtubos de $0,2 \mathrm{~mL}$ contendo: $250 \mu \mathrm{M}$ dNTPs, 2,5 unidades de Taq DNA polimerase, $0,26 \mu \mathrm{M}$ de cada primer, tampão de reação (50mM TRIS; $2,0 \mathrm{mM} \mathrm{MgCl}$; $20 \mathrm{mMKCl} ; 250 \mu \mathrm{g}$ de albumina de soro bovino; $1 \% \mathrm{de}$ ficoll 400; $1 \mathrm{mM}$ de tartrazina), 67,5ng de DNA genômico e água para completar os $30 \mu 1$. Foi utilizado o seguinte programa: 35 ciclos de $94^{\circ} \mathrm{C}$ para desnaturação, $58^{\circ} \mathrm{C}$ para anelamento e $72^{\circ} \mathrm{C}$ para extensão, todos por 20 segundos, seguido de uma extensão final a $72^{\circ} \mathrm{C}$, por $5 \mathrm{~min}$, sendo utilizado termociclador PCT-100 (MJ Research, Inc.USA)

Após amplificação, $5 \mu 1$ foram submetidos à eletroforese em gel de agarose a $1 \%$, imersos em tampão TBE $(0,45 \mathrm{M}$ de Tris-Borato e $0,01 \mathrm{M}$ EDTA), a $100 \mathrm{~V}$, durante uma hora, corados com brometo de etídeo e visualizados em transiluminador de luz ultravioleta, visando a verificar a qualidade da amplificação.

Em seguida, aos $25 \mu 1$ restantes da reação de PCR, foram adicionados $5 \mu 1$ de uma solução constituída de três unidades da enzima de restrição DdeI, $0,3 \mu 1$ de tampão de reação $10 \mathrm{X}, 0,3 \mu \mathrm{l}$ de albumina de soro bovino a 5\% e água para completar $5 \mu 1$ submetidos à digestão em banho-maria, a $37^{\circ} \mathrm{C}$, por cinco horas. Após digestão, o produto resultante foi separado por eletroforese em gel de agarose a $2,5 \%$, durante oito horas, a $60 \mathrm{~V}$, corado com brometo de etídio e visualizado em transiluminador de luz ultravioleta e fotografado em câmara digital Kodak DC290 Zoom.

\section{RESULTADOS E DISCUSSÃO}

Desempenho agronômico

No primeiro experimento, foram detectadas diferenças significativas entre famílias e para o contraste famílias versus testemunhas, em relação à PT. A média das famílias foi de $519,2 \mathrm{~g}_{\text {planta }}{ }^{-1}$ e das testemunhas foi de $390,1 \mathrm{~g}$ planta $^{-1}$. Dessa forma, ficam evidenciadas a variabilidade genética e a superioridade dessas famílias em relação às cultivares testemunhas e, consequentemente, ao potencial produtivo dos clones.

Nos dois experimentos da safra das águas de 2005, ocorreram diferenças significativas entre os clones para todos os caracteres avaliados. É importante ressaltar que as médias de produção foram baixas, cerca de $468 \mathrm{~g}_{\text {planta }}{ }^{-1}$, em decorrência da incidência de requeima (Phytphthora infestans).

Os 180 clones selecionados para o alelo $\mathrm{Ry}_{\text {adg }}$ (ver adiante) avaliados na safra de inverno de 2006 apresentaram diferenças significativas entre clones para todos os caracteres avaliados, com exceção do PE. Diferenças entre as testemunhas foram observadas somente para PE e AT. O contraste clones versus testemunhas mostrou diferença apenas para AT e PG. A PT foi de 1055,6g planta ${ }^{-1}$, para os clones, e de 986,72g planta $^{-1}$, para as testemunhas.

As estimativas dos parâmetros genéticos variaram com os experimentos e caracteres estudados. Para a PT, as médias dos quatro experimentos foram de $38,5 \%$ para o $\mathrm{CV}_{\mathrm{e}}, 27,16 \%$ para $\mathrm{CV}_{\mathrm{g}}$ e de $64 \%$ para a $\mathrm{h}^{2} \mathrm{a}$. Esses valores são semelhantes a outras estimativas encontradas na literatura, em trabalhos de melhoramento da batateira (LAMBERT et al., 2005; SIMON, 2005; BENITES, 2007).

\section{Resistência à pinta preta}

$\mathrm{Na}$ avaliação da resistência à pinta preta, conduzida na safra das águas de 2007 , foram observadas diferenças significativas entre os experimentos conduzidos na ausência e na presença do patógeno para PT, PM, PE e AT. APT sofreu redução de $14,6 \%$ (831,54 para 709,54g planta $\left.^{-1}\right)$, resultado semelhante ao observado por SIMON (2005), que registrou uma redução de $12 \%$. Para os demais caracteres, ocorreu um pequeno incremento das médias na presença do fungo, sendo de 3,4\% para PM, 0,1\% para PE e de 4,8\% para AT. Apesar de significativos, estes foram de pequena magnitude e podem ser explicados pela menor competição entre plantas, em função da morte precoce causada pela Alternaria solani. O menor ciclo vegetativo pode ter contribuído também para a melhor AT, reduzindo a ocorrência de desordens fisiológicas.

$\mathrm{Na}$ avaliação da resistência à pinta preta realizada em 2008, ao contrário da anterior, não foi observada diferença significativa para a PT na presença e ausência do inóculo, sendo evidenciada, entretanto, para os demais caracteres. As médias para PT observadas foram baixas com 409,3g planta $^{-1}$, na ausência da doença, e de $398,3 \mathrm{~g}$ planta $^{-1}$, na presença. Para os demais caracteres, as médias na presença da doença foram inferiores, com uma redução da PG de $56,7 \%$ para $49,3 \%$, do PM de 80,6 para $74 \mathrm{~g}$ e do $\mathrm{PE}$ de 1,0608 para 1,0575 . A exceção foi verificada para a nota de AT, com um aumento de 2,19 para 2,28, devido à causa comentada anteriormente.

Observou-se, no ano de 2008, um pronunciado efeito de temperaturas elevadas e alta umidade, induzindo maior desenvolvimento vegetativo e menor translocação de fotoassimilados, promovendo uma redução drástica na expressão dos caracteres avaliados e, consequentemente, mascarando o efeito da doença, como descrito por MENEZES et al. (1999). 
A análise conjunta nos dois anos agrícolas evidenciou redução significativa na PT, PG e PE sob efeito da doença. Foi constatado o efeito de anos, da interação clones x anos e clones x inoculação x anos, ficando evidente a necessidade da avaliação em mais de um ano agrícola.

AACPD foi significativa para clones e para o contraste clones versus testemunhas, evidenciando a variabilidade de resposta à infecção com o fungo Alternaria solani e comprovando a existência de resistência genética. Apesar da significância observada entre avaliadores, não ocorreu interação clones $\mathrm{x}$ avaliadores, indicando uma concordância entre os avaliadores na classificação dos genótipos. Por outro lado, a significância da interação clones $\mathrm{x}$ anos mostrou um comportamento diferencial nas duas avaliações, reafirmando a necessidade da avaliação em mais de um ano. Níveis elevados de herdabilidade foram estimados para esse caráter, $88,1 \%$ e $87,2 \%$, nos anos de 2007 e 2008 , respectivamente, demonstrando a viabilidade da seleção e concordando com as estimativas obtidas por MARTINS \& PINTO (1996) e SIMON (2005).

\section{Clones portadores do alelo Ry}

A análise molecular permitiu a seleção de 180 clones (54\%) que apresentaram a banda de $321 \mathrm{pb}$, correspondente ao alelo $\mathrm{Ry}_{\text {adg }}$. Esse resultado está de acordo com a segregação esperada de 1:1, em cruzamentos entre clones simplex (Ryryryry), como é o caso dos clones JUG, com genótipos nuliplex (ryryryry), como ocorre em 'Chiquita'. Esse resultado também confirma a eficácia do marcador RYSC3 na identificação de genótipos com resistência extrema ao PVY, como mencionado por RIBEIRO et al. (2006).

\section{Clones portadores do alelo $\mathrm{Rx} 1$}

O marcador CAPS utilizado na seleção de clones portadores do alelo Rx1 mostrou-se menos eficiente na identificação de genótipos resistentes do que o preconizado por GEBHARDT (2006). Ocorreu dificuldade na obtenção de amplificações adequadas para clivagem, o que pode ser atribuído, entre outras causas, a algum problema relacionado à especificidade dos pares de primers, que manifestam muitas vezes anelamentos incorretos, gerando produtos não específicos de amplificações e inviabilizando a clivagem pela metodologia empregada. Dessa forma, dos 180 clones identificados como resistentes ao PVY, apenas 46 foram avaliados, dos quais 22 apresentaram o alelo Rx1.
Seleção de clones com resistência múltipla e desempenho agronômico - Dos 180 clones portadores do alelo $\mathrm{Ry}_{\text {adg }}, 60$ foram selecionados como os de maior nível de resistência a Alternaria solani. Destes, 20 foram selecionados por apresentarem alto desempenho agronômico, além das resistências já comentadas. Apenas sete foram submetidos à análise para identificação do alelo Rx1, dada a dificuldade para serem obtidas amplificações de boa qualidade, sendo apenas um genótipo identificado como resistente ao vírus X. As médias das cinco gerações clonais desses 20 clones e das cultivares 'Asterix', 'Atlantic', 'Chiquita' e 'Monalisa' são mostradas na tabela 1 .

$\mathrm{O}$ clone selecionado como resistente à pinta preta e portador dos alelos de resistência $\mathrm{Ry}_{\text {adg }}$ e $\mathrm{Rx} 1$ apresentou PT de 662,4g planta ${ }^{-1}$, sendo superior às testemunhas 'Monalisa', com 535,34, e 'Asterix', com 423,23 planta $^{-1}$. Esse clone destacou-se também em relação à $\mathrm{PG}$ e $\mathrm{PM}$, com 77,1\% e 101,4g, respectivamente, sendo superior às cultivares 'Asterix', 'Monalisa' e 'Atlantic', com médias de 48,2\% e 86,65g, $51,9 \%$ e $69,3 \mathrm{~g}$ e $63,86 \%$ e $75,34 \mathrm{~g}$, respectivamente. Apresenta ainda PE de 1,0681, superando a cultivar 'Asterix' (1,0651) e se aproximando de 'Atlantic' $(1,0718)$. Com relação à AT, esse clone foi melhor que as testemunhas 'Monalisa', 'Atlantic' e 'Asterix'. Entretanto, é necessário ressaltar que as maiorias das avaliações ocorreram em condições adversas, com temperaturas elevadas e alta umidade, sendo necessárias novas avaliações em condições de menor estresse ambiental.

\section{CONCLUSÃO}

O marcador SCAR apresentou resultado compatível com a segregação esperada na população, sendo eficiente na determinação de genótipos portadores do alelo $\mathrm{Ry}_{\mathrm{adg}}$. Já o marcador CAPS utilizado para identificação de genótipos portadores do alelo Rx1 mostrou ser de difícil aplicação prática, tendo em vista a dificuldade para serem obtidas amplificações de boa qualidade para a digestão com a enzima DdeI, sendo necessário o desenvolvimento de outro marcador com maior eficiência.

Do total de avaliado, foram selecionados 20 clones de alto desempenho agronômico, resistentes à pinta preta e ao vírus $\mathrm{Y}$, sendo um destes identificado também como portador do alelo Rx1. 
Tabela 1 - Médias de cinco gerações clonais para produção de tubérculos ( $\mathrm{g}$ planta $\left.{ }^{-1}\right)$, porcentagem de tubérculos graúdos (Graúdos), peso médio de tubérculos (em gramas), peso específico de tubérculos, notas de aparência, AACPD, índice de Mulamba e Mock baseado no desempenho agronômico (Índice1) e índice de Mulamba e Mock baseado na AACPD e diferencial de produção (Índice2) dos 20 clones resistentes à pinta preta e ao PVY e quatro cultivares.

\begin{tabular}{|c|c|c|c|c|c|c|c|c|}
\hline Clones & Prod & Graud & PMedio & Pesoesp & Apar & AACPD & Indice1 & Indice2 \\
\hline 05-01 & 713,61 & 93,44 & 186,73 & 1,0756 & 2,46 & 500 & 32 & 94 \\
\hline $50-03$ & 644,22 & 73,98 & 113,08 & 1,0748 & 2,50 & 443 & 79 & 126 \\
\hline $19-06$ & 892,55 & 64,75 & 119,13 & 1,0768 & 2,20 & 393 & 84 & 96 \\
\hline $28-03$ & 710,85 & 85,93 & 144,73 & 1,0607 & 2,52 & 250 & 88 & 51 \\
\hline $12-03$ & 815,32 & 70,97 & 97,91 & 1,0711 & 2,75 & 352 & 90 & 21 \\
\hline $21-03$ & 787,13 & 79,47 & 128,89 & 1,0648 & 2,26 & 421 & 94 & 66 \\
\hline $17-04$ & 662,37 & 77,12 & 101,45 & 1,0681 & 2,47 & 309 & 100 & 123 \\
\hline $36-02$ & 679,53 & 75,82 & 91,99 & 1,0723 & 2,32 & 370 & 114 & 136 \\
\hline $54-02$ & 626,79 & 84,62 & 118,12 & 1,0653 & 2,34 & 456 & 114 & 131 \\
\hline $24-02$ & 717,84 & 82,98 & 128,75 & 1,0655 & 1,79 & 391 & 115 & 42 \\
\hline $18-04$ & 717,76 & 78,25 & 99,55 & 1,0666 & 2,25 & 409 & 117 & 58 \\
\hline $40-02$ & 842,28 & 79,46 & 109,68 & 1,0636 & 2,09 & 400 & 117 & 62 \\
\hline $39-08$ & 615,93 & 79,49 & 93,53 & 1,0681 & 2,82 & 345 & 120 & 64 \\
\hline $27-03$ & 718,35 & 69,31 & 96,83 & 1,0702 & 2,29 & 399 & 124 & 138 \\
\hline $21-10$ & 854,17 & 68,54 & 95,95 & 1,0719 & 2,05 & 387 & 127 & 55 \\
\hline $01-05$ & 514,46 & 81,39 & 111,27 & 1,0635 & 3,18 & 395 & 128 & 79 \\
\hline $45-07$ & 741,58 & 66,54 & 144,66 & 1,0610 & 2,31 & 449 & 134 & 66 \\
\hline $39-07$ & 713,20 & 76,32 & 103,39 & 1,0640 & 2,17 & 402 & 137 & 99 \\
\hline 51-04 & 815,69 & 77,37 & 106,96 & 1,0627 & 1,89 & 353 & 138 & 61 \\
\hline $19-03$ & 743,06 & 70,26 & 110,53 & 1,0654 & 1,92 & 395 & 139 & 33 \\
\hline 'Chiquita' & 738,81 & 60,85 & 108,78 & 1,0653 & 1,96 & 575 & 165 & 250 \\
\hline 'Atlantic' & 873,14 & 63,86 & 75,34 & 1,0718 & 2,03 & 501 & 167 & 92 \\
\hline 'Asterix' & 535,34 & 48,23 & 86,65 & 1,0651 & 2,27 & 659 & 231 & 200 \\
\hline 'Monalisa' & 423,23 & 51,86 & 69,29 & 1,0604 & 1,55 & 619 & 305 & 220 \\
\hline
\end{tabular}

\section{REFERÊNCIAS}

BENDAHMANE, A. et al. High-resolution genetical and physical mapping of the Rxgene for extreme resistance to potato virus $\mathrm{X}$ in tetraploid potato. Theoretical and Applied Genetics, v.95, p.153-162,1997. Disponível em: <http:// www.rothamsted.bbsrc.ac.uk/ppi/pubs/kostya/ Rx\%20mapping\%201997.pdf>. Acesso em: 20 abr. 2008.

BENITES, F.R.G. Seleção recorrente em batata visando tolerância ao calor. 2007. 90f. Tese (Doutorado em Genética e melhoramento de plantas) - Programa de Pós-graduação em Genética e melhoramento de plantas, Universidade Federal de Lavras, MG.

BRUNE, S. et al. Novos progenitores de batata imunes a PVY e PVX e resistentes à pinta preta. Horticultura Brasileira, v.17, n.2, p.173-174, 1999.

BRUNE, S. et al. Embrapa/CIP-PP1=018 e Embrapa/CIP039: novos clones de batata resistentes à pinta preta. Horticultura Brasileira, v.16, n.1, p.90-91, 1998.

CHRIST, B.J.; HAYNES K.G. General combining ability for early blight resistance from open pollinated $4 \mathrm{x}-2 \mathrm{x}$ early blight resistant potatoes. American Potato Journal, v.74, p.422423, 1997.
COCKERHAM, G. Genetical studies on resistance to potato viruses X and Y. Heredity, v.25, p.309-348, 1970.

FLIS, B. et al. The Ry-f sto gene from Solanum stoloniferum for extreme sto resistant to Potato virus $\mathrm{Y}$ maps to potato chromosome XII and is diagnosed by PCR marker GP122- 718 in PVY resistant potato cultivars. Molecular Breeding, v.15, p.95-101, 2005. Disponível em: <http://www.springerlink.com/ content/w2110004728r8616/>. Acesso em: 18 mar. 2010. doi 10.1007/s11032-004-2736-3.

GADUM, J. et al. Desempenho agronômico e reação de clones de batata (Solanum tuberosum L.) ao PVY. Ciência e Agrotecnologia, v.27, p.1484-1492, 2003. Disponível em: $<$ http://www.editora.ufla.br/revista/suple_2003/art05.PDF>. Acesso em: 18 abr. 2010.

GEBAHARDT, C.; VALKONEN, J.P.T. Organization of genes controlling disease resistance en the potato genome. Annual Reviews Phytopathology, v.39, p.79-102, 2001. Disponível em: <http://arjournals.annualreviews.org/doi/abs/10.1146/ annurev.phyto.39.1.79>. Acesso em: 18 mar. 2010. doi. 10.1146/annurev.phyto.39.1.79.

GEBHARDT, C. et al. Marker-assisted combination of major genes for pathogen resistance in potato. Theoretical and Applied Genetics, v.112, p.1458-1464, 2006. Disponível em: 
$<$ http://www.springerlink.com/content/x45451t272267m25/>. Acesso em: 18 mar. 2010. doi 10.1007/s00122-006-0248-8.

HÄMÄLÄINEN, J.H. et al. Mapping and marker assisted selection for a gene for extreme resistance to potato virus Y. Theoretical Applied Genetics, v.94, p.192-197, 1997. Disponível em: <http:/ /www.springerlink.com/content/0xm6lfueqep8k610/>. Acesso em: 18 mar. 2010. doi $10.1007 / \mathrm{s} 001220050399$.

KASAI, K. et al. Development of SCAR markers to the PVY resistance gene Ry(adg) based on a common feature of plant disease resistance genes. Genome, v.43, p.1-8, 2000. Disponível em: $<$ http://article.pubs.nrc-cnrc.gc.ca/ppv/RPViewDoc?issn=1480$3321 \&$ volume $=43 \&$ issue $=1 \&$ startPage $=1>$. Acesso em: 18 mar. 2010 .

LAMBERT, E.S. Estrategias para o melhoramento da batata para condições tropicais. 2004. 142f. Tese (Doutorado em Genética e melhoramento de plantas) - Programa de Pós-graduação em Genética e melhoramento de plantas,Universidade Federal de Lavras, MG.

MARTINS, P. R.; PINTO, C. A. B. P. Capacidade de combinação de genótipos de batata para resistência a pinta-preta, produtividade e peso especifico de tubérculos. Horticultura Brasileira, Brasília, v.14, n.2, p.161-169, 1996.

MENEZES, C.B. et al. Avaliação de genótipos de batata nas safras das águas e de inverno no sul de Minas Gerais. Ciência e Agrotecnologia, v.23, n.4, p. 77-784, 1999.

MULAMBA, N.N.; MOCK, J.J. Improvement of yield potential of the Eto Blanco maize (Zea mays L.) population by breeding for plant traits. Egyptian Journal of Genetics and Cytology, v.7, p.40-57, 1978.

REIFSCHNEIDER, F.J.B. et al. Illustrated key for the evaluation of early blight of potatoes. Plant Prot Bull, v.32, p.91-94, 1984.
RIBEIRO, A.M. et al. SCAR marker for the selection of Ryduplex potato clones immune to Potato Virus Y. Crop breeding and applied biotechnology, v.6, n.1, p.1-8, 2006. Disponível em: < http://www.abhorticultura.com.br/biblioteca/arquivos/ Download/Biblioteca/45_0460.pdf>. Acesso em: 18 mar. 2010.

ROSS, H. Potato breending: problems and perspectives. Berlin: Verlag paul Parey, 1986. 132p.

SAS INSTITUTE. SAS/STAT user's guide: version 8. Cary, 2000. Software.

SATO, M. et al. Potato virus Y resistance gene, Ry chc, mapped to the distal end of potato chromosome 9. Euphytica, v.149, p.367-372, 2006. Disponível em: <http:/ /www.springerlink.com/content/n 164614 u 7 x 21 / $? \mathrm{p}=\mathrm{d} 0 \mathrm{c} 0 \mathrm{c} 535857 \mathrm{a} 4910 \mathrm{a} 8 \mathrm{~d} 8 \mathrm{f} 4 \mathrm{a} 62 \mathrm{db} 04827 \& \mathrm{pi}=59>$. Acesso em: 18 mar. 2010 .

SHANNER, G.; FINNEY, R.E. The effect of nitrogen fertilization on the expression of slow-mildewing resistance in knox wheat. Phytopathology, v.67, n.8, p.1051-1056, 1977.

SILVA, O. A. et. al. Identificação de clones de batata imunes ao PVX e PVY, adaptados à região Sul de Minas Gerais. Summa Phytopathologica, Piracicaba, v.26, n.4, p.297-300, 2000.

SIMON, G.A. Interação famílias por ambientes e seleção de clones de batata resistentes à pinta preta e tolerantes ao calor. 2005. 114f. Tese (Doutorado em Genético e Melhoramento de Plantas) - Programa de Pós-graduação em Genética e melhoramento de plantas, Universidade Federal de Lavras, Lavras, MG.

SONG, Y.S. et al. Mapping of extreme resistance to PVY (Ry sto) on chromosome XII using anther-culture-derived primary dihaploid potato lines. Theoretical Applied Genetics, v.111, p.879-887, 2005. Disponível em: <http://www.springerlink.com/ content/g2601×634888x008/>. Acesso em: 18 mar. 2010. doi 10.1007/s00122-005-0010-7. 